\title{
Media Art Therapy as a Helping Tool for the Personality in the Information Age
}

\author{
Olena VOZNESENSKA \\ Institute of Social and Political Psychology, National Academy of Pedagogical Sciences, Ukraine \\ Ukrainian Art Therapy Association \\ voznesenska@gmail.com
}

\begin{abstract}
Media art therapy as an opportunity for self-expression through the media creativity is an effective strategy to preserve psychological health and prevent media traumas. The development of media art therapy is a natural part of the postmodern art therapy development path. The usage of the art therapeutic technologies enables the facilitation of media consumers "exit" from the "passive consumers" roles. Media art therapy creates the environment that helps to express the accumulated feelings including those from the interaction with media, thus it helps to prevent media traumatism and expand the level of personal media culture. The application experience of media art therapy (namely, the creation of plasticine cartoons) proved the capability of the method to overcome the psycho traumatism consequences to solve the conflicts and could be used to support the peacebuilding initiatives by sharing the content on Internet.
\end{abstract}

Keywords: media art therapy; telecommunications; psychological trauma; social rehabilitation; Ukraine;

DOI: http://doi.org/10.24818/ejis.2019.04

\section{Introduction}

Media and communications play an extremely important role in our life and expand capabilities of every modern person. Nonetheless, there are multiple self-expression and self-affirmation possibilities in modern societies that have their other side also called as "dark side". Information influences cause humans to divert from nature, from their essence and even cause the mental traumatism i.e. media traumatism. With an intensive media expansion in all spheres of life it is necessary to find ways to prevent possible negative media-related outcomes.

Under the conditions of the information explosion when the forms and means of media, interactions are being changed the art as the creative reflection of the reality is being changed too. The artist reaches the new level of interaction with his or her audience. Each and every human can become and artist! New media devices allow us to create incredible media products: photos, videos, collages and even cartoons with as little help as a simple smartphone can provide.

The existence of art therapy and media art leads us to the conclusion that they can be combined for the development of the art therapy as the method to help a personality to overcome the consequences of the media traumatism and to enrich the method through the opportunities provided by the modern technologies. Nowadays media therapy as the method of healing the personality through the means of art demands the cognition of new possibilities provided by the information world so that we get a new understanding of the healing mechanisms through the media applications in the creative process.

The purpose of the article is to present the experience of using media art therapy to overcome the consequences of psycho-traumatism, conflict resolution and peace-making under the war conditions. 


\section{Psycho Trauma and New Challenges in the Information Age}

The present state of Ukrainian society makes it impossible to stand aside its problems including social and economic crisis, hybrid war, information influences, military campaigns in the East of Ukraine and the annexation of part of Ukrainian territory. People's reaction on these events defines a collective trauma: personal shocked reactions are perceived not as an individual but rather mass experiences shared by a great number of people. The collective trauma appears when the society feels the threat for its collective identity. Trauma is a crisis that destroys the ordinary life frames so that they cannot be restored. The new frames appear instead of the old ones and sometimes this process can last for many generations.

The society affected by the collective trauma experiences different emotional states and behavioural modes caused by the changes in the outer environment. People lose the typical confidence in their self-security, the trust in the political leaders and public institutions. Under the conditions of the collective trauma they can be affected by panic and anxiety.

Inside the information societies trauma is spread with the help of different media, shared through mass media, social media and speeches of public political persons.

During the hybrid war that caused the systematic destructive information effects the issue of the prevention and healing of the media traumatism consequences is really relevant. The mass usage of social media causes the instant information waves that share information that cannot be verified. These waves affect spiritual and moral state of the personality and the society and causes media traumatism. We approach media traumatism as a brand-new kind of psycho traumas inside the information society (Voznesenska and Sidorkina, 2016). The specific feature of media traumatism is media as a source of trauma. Media trauma as any other kind of psycho trauma is related to the strong emotional experiences of a human. The event is not happening directly with a human but the perception of the event through the media: Internet, TV or other media makes a person feel as if he or she is a participant of the event. People seem to recognize who is who and who is right and wrong. While everything a person observes is just an interpretation / production of the event created by the media. Let's take a shock trauma known as "I am a witness" and a secondary trauma that helps others to get the trauma as well. People lose the sense of self security, trust in political leaders and public institutions.

Media trauma is a psycho trauma that appears under the influence of media tools, media messages, media content. It is a harmful reaction to an emotionally significant event affecting the meaningful spheres of human existence. It is associated with strong stressful effects on the psyche, a life threat. The threat should not be real but can be perceived as a threatening and violating the sense of security. The latest historical events in Ukraine have caused media traumatism of the Ukrainian population. The intensity of the outer influence can be comparably low but should be constant. Media traumatism is related to the constant emotional experiences that cause the life quality to decline (many Ukrainians are suffering from insomnia, emotional burn-out, have a "news dependence", fears, increased level of stress, the level of post-traumatic syndrome is being developed as well as somatic diseases etc.).

A good example of media traumatism is the so called "fake" i.e. "faked in advanced" information that is released in mass media to provoke certain emotions (horror, panic, aggression). The "fake" affects the emotional state of humans and can cause certain modes 
of human behaviour. The constant flow of such negative news can lead not only to the passive reactions of the society (loss of faith) but also to depression, psychosomatic disorders. People that fill in their free time with TV, faked or real news that they see on the screen are perceiving the events as being meaningful for their lives. This process can cause the secondary trauma.

We have defined three implicit kinds of media traumas: influence of mental state through the perception of media information, social contacts disorder, and violation of human privacy.

The identification of the ways to overcome the media traumatism and collective trauma of the Ukrainian society is through the cognition of their sources and mastery of modern media technologies. The top important part of the mastery of collective trauma is the legitimation of traumatic experiences at the cultural level. The pivot, denial, avoidance are the neurotic mechanisms to prevent the traumatic experiences. The important step towards the healing of collective trauma is the creation of pieces of art that are connected with the traumatic events, e.g. statues, photo albums, books of memories, exhibitions, museums, movies as kinds of collective testimony. The overcoming of collective trauma is possible through the collective experience and shared creation of art.

\section{Art Therapy in the Postmodern Time}

Media art therapy as an opportunity for self-expression through media creativity is an effective strategy for the preservation of mental health of Ukrainian population, the prevention of media trauma and strengthening of media immunity. We propose to combine therapy, art and the newest media technologies. Media art therapy is the newest form of art therapy. Its basis is the usage of modern media that is a distinctive feature of the method.

We define art therapy in a broad sense as a system of psychological help based on the art, creativity and establishing of psycho therapeutic relations.

Art therapy combines a number of the specific methods that help personality to heal through the art (literature, music, fine art, dancing, theatre etc.). By "healing" we understand the state when client reaches the state of "completeness" of one's psycho first of all i.e. treatment and prevention of psych disorders, rehabilitation, correction of behavioural and communication patterns, achievement of the client's high quality of life and the development of the inner potential. Art is a means of psychotherapy per se as it is a reflection of the existential meaning of "self", human's inner being and the interaction between "the self" and the outer reality.

The development of media art therapy is a natural consequence of the present development stage of art therapy per se i.e. postmodern time. Postmodern art therapy is a methodological approach in art therapy based on the postmodern philosophy, science and culture. Postmodern (from the French postmodernisme) - is a XX century worldview and art trait. The representatives of this trait have abolished the modern principles and stated that a piece of art doesn't represent a reality but creates a new reality because the product is created in the consciousness of the audience through the perception process. Every observer is a cocreator as he or she are understanding the symbols and inputs his or her own meanings to the end creative product. Postmodern is guideline for a new post-industrial society that has come after the industrial one. Inside the postmodern people are using the ready-made shapes (derived artistic images, ideas, pieces of art, multiplication, remakes, additions etc.); 
are operating a few different meanings putting them into certain contexts; are using eclecticism - mixing and combining different by type and incompatible notions (ideas, elements, views, images) to go beyond their oppositions and to create the completeness inside the system; are promoting plurality and are denying authorities; are ready for the communication and dialogue to reach consensus with each and every culture; people tend for archaic, myths and are overwhelmed with symbols of collective subconsciousness, are using games, fakes, kitsch, irony and absurd; are aimed at participation and process rather than on the result.

Alter-Muri (1998) defines the following features of postmodern art therapy: the dialogue nature of common reality created by psychotherapist and client with the application of visual images that are given certain meanings; the denial of universal symbolic meanings; the attention to client's cultural identity and "integration of personal therapy and social problems, social actions of a client". Thus, media art therapy becomes a reflection of human obligations towards the society.

To have a better understanding of what media reality is and to understand the role and place of art in the virtual reality and the role of virtual reality in art, we should study media art as a social phenomenon. Contemporary artists as their predecessors are looking for stimuli for their creativity in different fields of knowledge. Today artists have started to create their pieces of art inside the information environment with the help of modern technologies. Media art is using modern digital technologies like Internet, smartphone and any other ways to transmit the signal as an art environment. There are three defining features of media art as the most contemporary kind of art: art systems, scientific and industrial research and political/cultural media activism. Media art is thus placed on the intersection of art, science and politics. These all makes media art therapy a useful tool during social conflicts and shocks.

A virtual reality is extreme and attractive, any computer gives a person the access to it. It is a quasi-real space, "an improved" copy of the world (that works faster, is more informative and more secured). It is a 3D space with a new relations and cognitions of time and distance, with different movement principles, tempos, actions and other ways of communications and human relations. Time and space that used to be sustainable, constant and continuous are losing their defined nature inside media reality. Balashova (2009) states that media art as an artistic action not only defines and reflects the peculiarities of the present state of society but also tries to correct the state for the survival and development of social system.

The features of media art are the following: flexibility, the absence of borders and limits including the limits in between the author and the audience and the uncertainty of national cultural code due to the globalization processes. Media art is an art for the creativity and self-expression. Media art is defined by the shift of artist's attention from the aim to the process. And this process is pretty much influenced by the development of technologies that has enlarged the tools to be used by artists.

The piece of media art is a communication system. In media art the artist is providing the message and the recipient is filling it with his or her own meaning (ibid). And the artist's aim is not only to demonstrate or impose his or her own vision and personal viewpoint but to communicate with the audience and involve them into the creative dialogue (Horyunova, 2000). The communication as the basis of modern society becomes the meaning and the content of art as an activity. The communication is preceding meanings and information. Modern artist is just creating a context that is being filled with the meaning in the audience's/recipient's consciousness so that audience becomes a co-author and a co-creator 
to some extent. The piece of art is not only observed but it demands an active participation from the audience, the interference into the creative process.

For media art it is typical to be interpenetrating, adding and bringing closer to each other certain phenomena. On the one hand it is a conversion of different kinds of media (audio, video, texts etc.), on the other hand these are new ways of doing provided by multimedia technologies and are substantially enlarging artist's capabilities and help him or her to simulate new perceptive environment putting the audience deeper into the author's reality.

But media art is not a substitution of the traditional kinds of art and cannot replace them. This is a separate part of the contemporary culture. Media art product has no utility meaning. It cannot be sold, kept or destroyed. Media art works for the self-regulation of media culture to educate a new type of media age human that is used for a modern communication system.

\section{Media Art Therapy: Definition, Distinguishing Features and Application Mechanisms}

The name of the "media art therapy" method is made of the three words that together create a new one:

- Media are channels, tools and technological engines to record, save and transmit the information. Information sharing is a substantial part of the information society's life, so media technologies are mediators for human activities per se. Media are communications and conditions for human activities.

- Art is a kind of cognition and reflection of the reality (author's inner and outer reality) inside human consciousness as certain emotional art images towards certain aesthetic ideals. Art is one of the ways to cognize the world and also a way to educate people about politics, moral and visual world;

- Therapy (from Greek therapéia, $\theta \varepsilon \rho \alpha \pi \varepsilon i \alpha$ - healing, treatment) is a process to take away or eliminate any type of illness, to normalize the disturbed life processes, to heal and recover.

So, media art therapy needs modern communication systems to heal the personality inside the artistic space and through the artistic tools. The development of art therapy is possible due to the development of information culture that is being open, diverse, multicultural, virtual, uncertain and globalized. Media art therapy is not just media art inside the therapy, but it is also any kind of media inside art therapy that is used for creative process (Voznesenska, 2017). So, these are two ways to apply art inside the therapy: 1 - recipientmode (passive) - the perception of media art pieces: movies, photos etc. Masterpieces have a very strong healing potential; 2 - creative (active) - creative self-expression, client's own creativity with the help of media: creation of media products with the help of art therapist. Widely known kinds of such assistance are phototherapy and film therapy. Certain information technologies are used in both ways but passive way (healing through the perception of the media content) is a prevailing one in the world practice. We are proposing to use active types of healing: the creation of your own media content, media creativity for the self-expression. The multimodality of the visual space provides one with the opportunity to bring life to one's story or fairy-tale (as simple as creating a gif animation) or by adding the electronic music to your piece of art that is already an art therapy. 
During the application of media tools to the therapy process the establishment of a connection is done much easier through the ordinary or even trivial attitude to the media technologies. The non-verbal communication helps an art therapist or any other person to better understand a human. The huge creative potential of modern media tools helps to make use of the art expression as an important art therapy. The trivia of media creativity when people are making photos, do storytelling and self-promotion, create demotivators as the kind of social creativity, these all help to take away the creativity-related barriers and fears ("I cannot draw", "I'm not an artist", "I cannot make it" etc.). Art therapy of such a kind do not distract people, on the contrary, you can use it in your daily life to make photocollage, invite friends to make common cartoon to celebrate an important date or holiday.

The application of media art therapy creates an opportunity to work with those who cannot participate in art therapy groups (share emotions and voice over own thoughts to others) for some reasons. This helps the adaptation and re-adaptation of people into the community, creates the environment for social activities and is a feature of media art per se. These all creates an active social role for a client.

Feedback is very important for media art therapy: it helps new ways of creativity to appear, the new meanings to be formulated and projections on self-produced art to be easier adopted. The dissemination of media creativity products on Internet allows one to get emotional support, recognition and the appreciation of value and meaningfulness. With the help of Internet technologies media art therapy is increasing one's number of communication strategies and client's actions, it facilitates the interpersonal learning.

The mechanisms of therapeutic influence in media art therapy are: catharsis, creative expression (through new media), emotional support (that can grow significantly if pieces of one's own creativity are shared through Internet), awareness of one's own uniqueness, group identification (sense of belonging to the community), value of communication and joint creativity awareness, projection, reflection, awareness and construction of new meanings. The development of media competence in the process of media creativity leads to the increase of self-evaluation and to the improvement of communication quality. This is very essential for working with psycho traumatism.

Additionally, the application of art therapeutic technologies enables the facilitation of media consumers "exit" from the "passive consumers" roles that is extremely important under the conditions of the information war. The development of media competences as the result of media creativity increases one's self-esteem and to establish a communication. The application of media art therapy helps to get skills to identify the media influence tools, media manipulation, raise your own media culture to prevent media traumatism in future, to prevent psycho-emotional disorders, has a positive influence on the reflexive position development during the interaction with media. This is an important step towards the formation of healthy, active and conscious personal position to media.

\section{Methodology}

The training «Art Therapy Techniques for Conflict Resolution and Peace-making» inside the «Women's Voice has a Power» project was implemented by the Human Rights Foundation and was funded by the Institute for International Cultural Relations (Institut für Auslandsbeziehungen) by means of the German Ministry of Foreign Affairs (Auswärtiges 
Amt). The training was based on the art therapy methodology in its wide sense i.e. a healing method that uses any kind of art and particularly the media art therapy.

The participants were civic activists from different regions of Ukraine including the temporary uncontrolled territories (Dnipro and Dnipropetrivsk region, Sumy, Uzhhorod and Zakarpattia region, Kharkiv, Zaporizhzhya, Chernivtsi, Donetsk and Luhansk regions). One third of the participants were people who are originally from these regions and the rest were temporary displaced people as the result of the four-year lasting war-conflict in the East of Ukraine. The total number of participants was 26 people. The majority was women (24 people). Seven people were psychologists, the rest were creative professionals, philologists, medical workers, lawyers and others. The age varied from 20 to 62 . But all the participants were united by the active social role, the will to establish better relations with others, to solve conflicts and to do peacebuilding.

One of the training aims was to overcome the psycho-traumatism consequences. The observation of clients who were not civic activists, did not visit the territories affected by the war, were not temporary displaced people proves that even such people live under the constant resource mobilization, fear and feel hidden anxiety and anger. These all are the consequences of our society's collective trauma - the war trauma. Some of these people suffer from secondary trauma i.e. media traumatism.

Training design was done together with Volodymyr Savinov. The training consisted of combination of individual and teamwork, the application of different creativity types, the consecutive application of art therapy, media art therapy, body-oriented therapies, playback-theatre and drama therapy.

The aim of the training was to learn art therapeutic tools and methods to organize separate for the conflict resolution and peacebuilding, creativity development, flexibility of personality, reflection and mastering of new behavioural patterns inside the conflict to do their own peacebuilding projects in Ukraine. Total training duration was 36 hours.

\section{Results}

The group work, common creative activity - painting, fine art, plasticine modelling or clay crafting helps not only to free the unpleasant feelings but to facilitate the self-expression, establishment of the communication and what is more important during the conflict times to get the support of others, to enrich the behavioural patterns and to become a creator, to create something new and unique.

Following the introduction and the work with interpersonal conflicts of the participants, the consequences of psycho traumas, studies of self-interaction and conflict resolution patterns, expression of feelings that result from the conflicts it was important to combine the participants to reach the common aim. At this stage we proposed the participants to try a new art therapy method i.e. media art therapy. The aim of the media art therapy exercises was to understand the possibilities of the latest informational society technologies; to learn tools and methods to create the peace-making content. All the participants co-created cartoon called "Own Truth" (Own Truth, 2018). At first the idea to make a cartoon created a disambiguation since cartoons were perceived as some "childish activities". But later on, the majority of the participants were fascinated by the process and some of them even used the free evening time to select the proper soundtrack. The screening of the cartoon at the 
end of the training made people tremble and fascinated them. It was hard to believe that they created it by their own.

We have chosen animation as the commonly familiar since everybody's childhood kind of screen art. Animation as an art appeared two decades earlier than classical cinema and up until today contributes to the modern "screen reality". Animation has fundamentally different organization of the production process than in the movies i.e. making separate shoots. It expands the experimental boundaries and the ability to embody fictional images.

The plasticine animation was proposed for the implementation. Plasticine was chosen as the material that contributes the best as the response to the strong feelings of conflicts and traumas of war: fear, anger, aversion, etc. Plasticine is often used to work with aggression, phobias, fears and frustrations that is extremely important for people with psycho traumas who lack opportunities to express their feelings or who are full of their fears. Such work approach helps to heal negative states by the manipulation with the materials, it decreases the probability of auto-aggression, client violence towards the others. As the result people lower the level of body tension, shift from the emotional tension, an opportunity to "meet" with the unpleasant feelings. The cognition of the body changes helps the client to integrate the derived experience. Plasticine doesn't require much physical efforts; it influences the creation of solid images; brings bright colours that facilitate creativity and spontaneous reactions; it enables to creatively portray any kind of topics. These all empowers cognition and correction of emotions and feelings. The plasticine images can be easily modified at any time that enables changes and transformations, provides the feeling of control over the situation and helps to practically apply the knowledge about the right for a mistake. These features of plasticine promoted its usage for the training as the aim was to overcome the consequences of the psycho traumas of the participants, to master new skills, to create the peacebuilding cartoon.

Activity of creating a fine art in many cases is a very important communication tool that enables a person to build a more harmonious relationship with the outside world. The participants tried themselves in the role of scriptwriters, directors, animators, operators, video editors, sound directors and so on. Each of the roles has its own features and enables participants to express certain sides of their personalities. The director should see the cartoon as the whole, he or she is in the meta-position, he/she sets up particular screens. His/her role could be named as the project manager's role. The attention, carefulness and precision are crucial for the operator. And the person responsible for the video editing has a very creative task to set up the duration of each shoot, its emotional intensity and so on. The same applies for the sound director who is applying sound to the ready-made video. None of the training participants has tried to create animation before. It was a new experience for each of them.

Not only the teamwork and creativity that were important during the execution of media art therapy tasks but also the opportunity to gain the result of creating something beautiful and then sharing it with others. This provides the resourceful feeling of mutual support and the trust together with the understanding of self-wills and demands. Additionally, this provides the resource for the interiorization of the learnt skills by each of the participants.

The work on the cartoon creation is made of four stages (Holubeva, 2012).

1. The first is the preparation stage that is about the idea creation, script writing and directing. The main characters of the future cartoon are identified at this stage. By the end of this stage each of the participants has a more or less clear image of the future cartoon. 
The idea is approved by all the group members. This ensures that each and every has his or her sense of the ownership of the script.

We did the "birth" process of the cartoon in the following way. The theme of the animated film was determined by the theme of the training - conflict and peacebuilding. All the participants were writing 3-5 associations with the word "conflict". When the individual lists of associations were done, people were all divided into groups of two and were to choose one common association. The groups of two merged into groups of four. And again, they were to select one common association from their lists. The groups of four then made the groups of eight and were to select the common association again. These all resulted into three images (all three groups were functioning in the same manner at the later stages): bombe, cannon and an apple of discord. These images were not random ones as many participants have left the war zone in the East of Ukraine. For them as for many other Ukrainians word "conflict" means "war conflict" that was portrayed in their associations as well.

The next task was to make a common association with the help of plasticine. Each of the groups were to give certain features to their character as well as his or her personal history. As it appeared from their stories none of the characters was not planning to make conflicts or war. The cannon was old and had not been used for the war campaigns for a long-long time. It was standing as a statue and was fed up with the war that was a reflection of the feelings of our participants. The Mr. Bombe was rather a comic character who was unaware of his own capabilities. The most detailed one was an image of the apple of discord that contained a worm inside it named "Mario". Mario knew the life, was helping others to resolve the conflicts and could see the situation from the other point of view. The characters and their stories were then presented to all the participants.

During the common discussion participants tried to answer the question why it happened that all three characters had met each other. As a result, we had got a pre-script: «Own Truth. In every conflict each side has its own truth. Once upon a time Mr. Bombe and Cannon had met each other. They liked the same apple and they had started to argue about its colour. The conflict ended up with a big war. When the silence came and the wind took all the ashes away, the peacebuilder worm Mario showed to Mr. Bombe and Cannon that an apple was two-coloured - green from the one side and red from the other side».

Participants defined seven episodes - the meaningful pieces of the cartoon: the appearance of an apple, the appearance of Mr. Bombe and Cannon, the argue for the apple's colour (it was metaphorically shown as the growing balls: the red one was on Mr. Bombe's side and the green one was at Cannon's side); the culmination was represented by two balls moving towards each other and then smashing, causing explosion; the appearance of the worm; the resolution of the conflict between Mr. Bombe and Cannon.

2. Second stage is shooting. The parts are making characters alive. Nikon camera and a tripod were used at this stage. The stage was made from the table with a big white sheet of paper on it. There were natural lights. All the participants took their part in animating and moving the characters during all the shoots. Seven episodes were made with the help of approximately 300 shoots. 1 second of video needed 24 shoots and sometimes we had to redo the shoots for one or more times.

During the shooting process participants were modifying the original script - edited the episodes, corrected the script. There were two main types of modifications identified by $\mathrm{O}$. Hovubeva: hyperbolization (more attention and emotional tension in some episodes); simplification (the inability to create the complicated script patterns made people to 
transform the original images) (Holubeva, 2010). The limited time of training disabled people to complicate the scenery and play with different planes.

There were main rules taken during the shooting process:

- Each second of cartoon consists of 24 separate shoots;

- There shouldn't be any simultaneous movements of different characters (simultaneous movements result from the subjective perception of the audience);

- Camera should be fixed on the tripod, so we have a continuity of the picture.

3. Assembling is the third stage of cartoon-production process. It was done on the laptop with the help of the Movavi (version 5.2.2) software program. Famous songs and melodies were used as the soundtrack to stress the mood of each episode and make a stronger effect of the video itself.

The integration of the shot material (separate photographs) into a complete image and adding up music to it could be defined in terms of psychological help to overcome the consequences of the psycho traumatism as the restoration of the completeness of the world after fragmentation caused by the traumatic events. The big number of fragments symbolizes the destroyed picture of the reality that was dissolved after the traumatic event. The complete image is made piece by piece and each of them has strong colourful effects. The assembling helps to do a new sense-making of the traumatic experience. Without this recognition one cannot achieve the post traumatic growth.

Common creative process ensures the experience of mutual support, reliance, renewed completeness where each and every sight and thought have their own places, where everybody can co-exist and co-create. The smooth group work is also crucial: everybody should feel contribution to the common creative process. The result is a big resource for the participants. This is the most emotionally positive stage for the group participants. The separated shoots and episodes assembled with each other and combined with music reached the final meaning.

4. The last is the viewers stage. This stage is about presenting your piece of art to the audience. The end of the cartoon-making as a kind of media art therapy is done by the real contact with the audience. One compares own feelings with the feelings of others and sees how the idea is being realized. The screen image now exists not only in one's head but gets meanings formulated by the audience. There is a dialogue between the media creator and the audience. The experience of your own screen creativity as a social phenomenon shows the existential meaning of the screen in our contemporary world. This is not just an opportunity to share your own achievements with others but to make your own contribution to the rehabilitation of the collective trauma, to affect the development of the society and to reach a new understanding of social media reality. These all happens because the perception of the media (screened) products depends on certain characteristics of the group: emotional unity, general cultural development level of the group, the increase and decrease of the emotional reactions and the group values. Media art pieces are powerful stimuli for the activation of complex psycho processes, and they cause the co-creation. Not only creation process is concerned but also a creative perception of commonly made media product.

The first presentation of the created cartoon was done at the end of the training. The audience consisted from the other tutors who didn't take part in the creation of the cartoon. The cartoon was published on the YouTube channel of the Whole-Ukrainian Civic Organization "Art Therapy Association" (Own Truth, 2018). 
There is another example of the media art therapy application to overcome the psycho traumatism. The cartoon was made during the educational and methodological seminar (practice-oriented training) «Media psychological tools for the prevention and overcoming of the media traumatism» provided by the staff of the mass communication psychology and media education laboratory of Institute of Social and Political Psychology of National Academy of Pedagogical Sciences of Ukraine by Olena Voznesenska (the author) together with Nataliia Obukhova and Nataliia Cherepovska.

The aim of the seminar was to teach the specialists of the assisting professions the methodology of media art therapy application for the work with children and teenagers; the media psychology tools for the enabling the inner resources for the overcoming of media traumatism; to search for the options of the common commune life. The participants were psychologists from different educational institutions from Slovyansk district of Donetsk region. The majority of them stayed in their cities during the war-campaign in 2014. The participants themselves had traumas caused by the war, terrorism. Additionally, a lot of kids in their schools has suffered from the war as well.

We used the method of the shoot-by-shoot work with the paper animation for the actualization of body experiences (Holubeva and Obukhova, 2014). The manipulations with visual human prototype are considered as a kind of body-oriented work. We had used the combination of individual and group creativity. Firstly, the participants created a puppet out of different parts: the head, the body, shoulders, forearms, hands, thighs, shins, foots. The parts of human bodies were drawn and then cut and then put together with needles.

The multiscreen culture of the modern information world has many obvious and hidden psychological consequences including those that harm minds. The application of animation tools helps not only to participate in the cinema culture but also to achieve the skills to identify the media manipulation, to increase one's media culture and to counteract the possible future media traumatism.

The second stage was about playing with the puppets to portray the object-subject relationships and to have an ecological way to recreate the traumatic emotional experience. The manipulation provides the hidden aim of the manipulator when the action is attractive to one of the communicators. During this game people are projecting their own bodies on the puppets' movements. The participants could trace their own behavioural patterns and realize the body limitations. By playing with puppets some people could get rid of the unpleasant body feelings connected with the traumatic experiences of the past.

Because of the limited time we offered to recreate the puppet movements in the cartoon without focusing on the script. The puppets were made from the ordinary white paper and for the decoration we used the bright painted A1 sheet of paper. The participants created their "fantastic cartoon world" by themselves. The shooting process was organized in the same manner as in the above-mentioned example. The assembling was done by a tutor and the soundtrack was chosen by the tutor too.

Interiorization of the experience achieved through the media art therapy training was done during the common observation of the cartoon by the comparison of feelings and the transformation of the emotional experiences (Animation with puppets. Slovyansk 2017, 2018). Participants admitted the changes in their body reactions and identified their typical body movements and movement patterns in the cartoon they made.

The experience of the media art theory application helped to increase the media culture of the participants through the mastery of new skills of media content creation. Additionally, these trainings helped each participant to share his or her feelings related to the war 
campaign as the majority of the participants was temporary displaced people from the combat zone in the East of Ukraine. Everyone could be heard, everyone had realized his or her traumatic experience, which was then translated into a symbolic form of the animated film. Such activities help to re-evaluate the traumatic experience, to achieve the higher level of consciousness and to overcome the consequences of media traumatism. The opportunity to share the cartoons on internet helped to get more support through the additional audience and their "likes". These all help to understand that the life continues, and the consequences of the media traumatism could be overcome.

Media art therapy as the application of media in art therapy process was used by us in different teenager and children groups, in family groups that take care of pre-school and school children. The method is applicable when there is certain level of media literacy of the adult and children participants, they should be aware how to use the camera, computer, Internet (nonetheless, our experience shows that through the time the more and more people have this type of literacy).

\section{Conclusion}

Today art therapy as a method of healing the personality by the means of art requires understanding of new possibilities of the information world, the emergence on a new level of understanding of healing mechanisms through the use of media in the creative process. The application of the media art therapy creates the environment to express the accumulated feelings including the ones that were created as the result of the interaction with media. That is an important condition to prevent the media traumatism and to raise the media culture of the person. Our experience has proven that media art therapy is an adequate method for resolving conflicts in real groups

The media art therapy method is applicable to the peacebuilding initiatives for the large communities. Today art therapy as a method of healing the personality by the means of art requires understanding of new possibilities of the information world, the emergence on a new level of understanding of healing mechanisms through the use of media in the creative process. The use of the media art therapy creates the environment to express the accumulated feelings including the ones that were created as the result of the interaction with media. That is an important condition to prevent the media traumatism and to raise the media culture of the person. Our experience has proven that media art therapy is an adequate method for resolving conflicts both in real groups and for the implementation of peace-making initiatives in large communities.

\section{References:}

Alter-Muri, S. (1998): Texture in the melting pot: Postmodernist art and art therapy. In: Art Therapy: Journal of the American Art Therapy Association. 15 (4): 245-251.

Animation with puppets. Slovyansk 2017 (Анімація з маріонетками Словянск 2017) (2018):

Available at: https://www.youtube.com/watch?v=I8kKjFLOnhU

Balashova, O. (2009): Net Art and the Paradoxes of the Contemporary Art (Net Art і парадокси сучасного мистецтва). In: Філософська думка. 6: 81-90.

Holubeva, O.Y. (2010): Screen as a New Dimension of Psycho Reality (Екран як новий вимір психічної реальності). In: Простір арт-терапії. 2 (8): 22-32.

Holubeva, O.Y. (2012): Animation Studio inside an Educational Institution (Анімаційна студія у навчаль-ному закладі). Київ: Видавництво «Шкільний світ». 
Holubeva, O.Y., Obukhova N. (2014): A Puppet: the Illusion of Choice (Маріонетка: ілюзія вибору). In: Простір арт-терапії: ресурси зцілення: Матеріали XI міжнародної міждисциплінарної науково-практичної конференції (м. Київ, 3-4 квітня 2014 р.). Чуприков, А.П., Найдьонова, Л.А., Бреусенко-Кузнєцов, О.А., Вознесенська, О.Л., Скнар, О.М. (ed.). Київ: Золоті ворота: 140-143.

Horyunova, O. (2000): Автор в зубах у «плохой машины». In: Русский журнал, 2000. Available at: http://old.russ. ru/netcult/20000222_gorun. html

Own Truth (Своя правда) (2018): Available at: www.youtube.com/watch?v=uJtCV0KfZGY.

Voznesenska, O.L., Sidorkina M.Y. (2016): Art-therapy in Overcoming Psycho Trauma: Practical Learners Book. 2nd edition (Арт-терапія у подоланні психічної травми: Практичний посібник). Вид. 2е: випр. та доповн. Київ: Золоті ворота.

Voznesenska, O.L. (2017): Media-art-therapy (Медіа-арт-терапія). In: Вознесенська, О.Л., Скнар, О.M. (ed.). Енциклопедичний словник з арт-терапії. Київ: Видавець ФОП Назаренко T. B.: 181-182. 